\title{
Quantitative characterization of the effect of biogenic silver-based nanoparticles on breast cancer cells by high content analysis
}

\author{
Celso Sant ${ }^{\prime}$ Anna ${ }^{1}$, Veronica Ferreira ${ }^{1}$, Mateus Eugenio ${ }^{1}$, Elaine Del Nery ${ }^{2}$, and \\ Wanderley De Souza ${ }^{3}$ \\ ${ }^{1}$ Instituto Nacional de Metrologia Qualidade e Tecnologia \\ ${ }^{2}$ Institute Curie \\ ${ }^{3}$ Universidade Federal do Rio de Janeiro Centro de Ciencias da Saude
}

July 2, 2020

\begin{abstract}
This study aimed to evaluate the antitumor potential and cytotoxicity induction mechanisms of green synthesized AgCl-NPs and $\mathrm{Ag} / \mathrm{AgCl}-\mathrm{NPs}$ through image-based high content analysis method. The antitumor potential of $\mathrm{AgCl}-\mathrm{NPs}$ and $\mathrm{Ag} / \mathrm{AgCl}-$ NPs was evaluated in breast cancer BT-474 and MDA-MB-436 cell lines treated with 0-40 $\mu \mathrm{g} / \mathrm{mL}$ AgCl-NPs or 0-12.5 $\mu \mathrm{g} / \mathrm{mL}$ $\mathrm{Ag} / \mathrm{AgCl}-\mathrm{NPs}$. Normal human retinal pigment epithelial 1 (RPE-1) cells were used for comparison. The growth rate of the RPE1 cells treated with AgCl-NPs or Ag/AgCl-NPs was little affected, and no significant changes in cell viability were observed. In these cells, the nanoparticle treatments did not induce lysosomal damage, changes in reactive oxygen species (ROS) production or a reduction in the mitochondrial membrane potential. Moreover, the percentage of apoptotic cells was minimally affected, reaching a maximum of $3.51 \%$ of the population. The level of BT-474 and MDA-MB-436 cell proliferation was markedly decreased, and cell viability was reduced by 64.19 and $46.19 \%$ after treatment with AgCl-NPs and reduced by 98.36 and $82.29 \%$ after treatment with Ag/AgCl-NPs. The cells also showed a significant increase in ROS production and loss of mitochondrial membrane potential, which culminated in an increase in the percentage of apoptotic cells. BT-474 cells also presented lysosomal damage when treated with the highest concentrations of both nanoparticle types, and actin polymerization was observed after exposure to Ag/AgCl-NPs. Together, the results obtained show overall cytotoxic effects of both AgCl-NPs and Ag/AgCl-NPs towards breast cancer cells with negligible effects against healthy cells, which suggests their promising anticancer and biomedical applications.
\end{abstract}

\section{Hosted file}

Ferreira et al_2020_Biotechnology_journal.docx available at https://authorea.com/users/ 338892/articles/465534-quantitative-characterization-of-the-effect-of-biogenic-silverbased-nanoparticles-on-breast-cancer-cells-by-high-content-analysis 

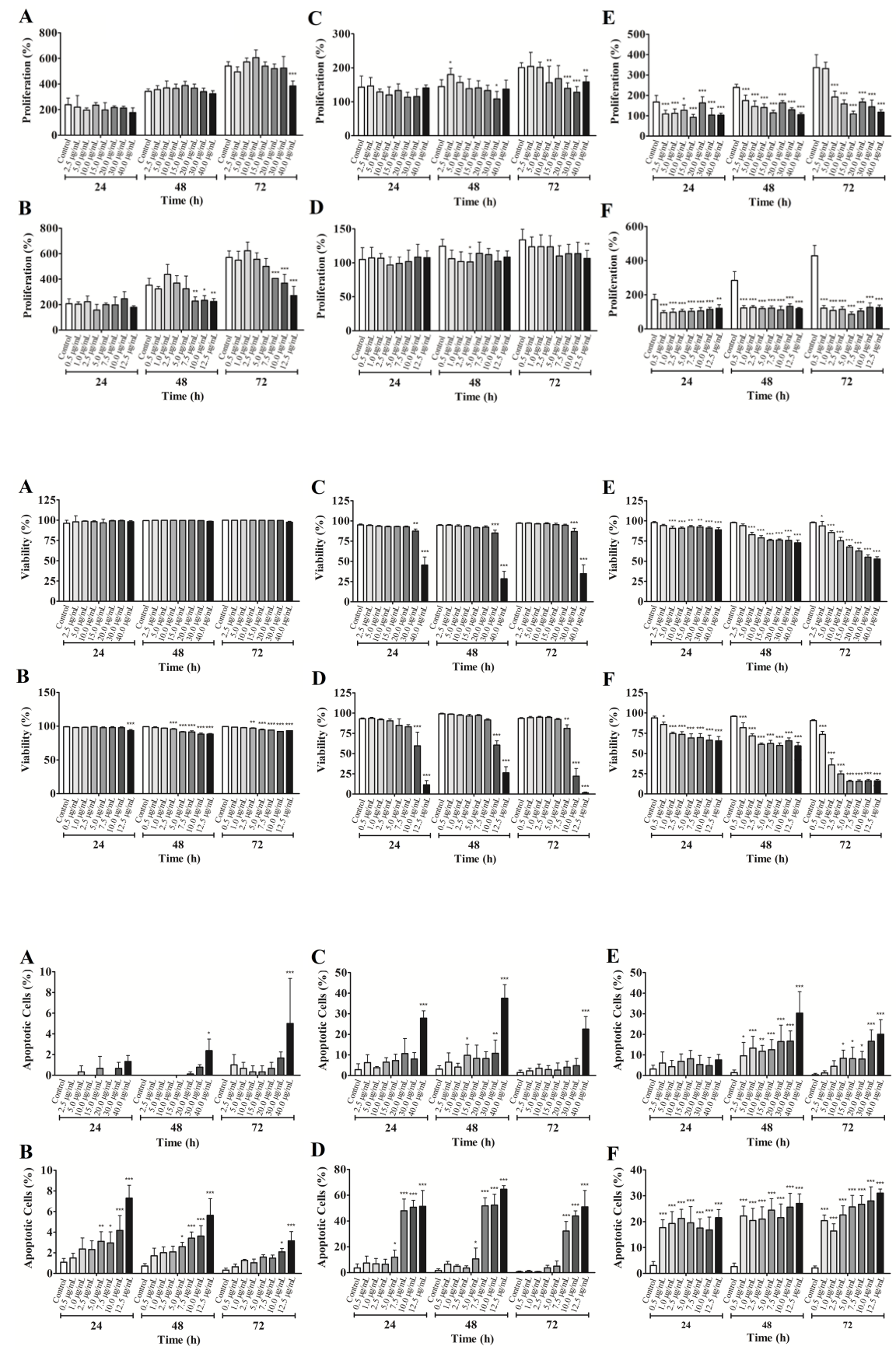

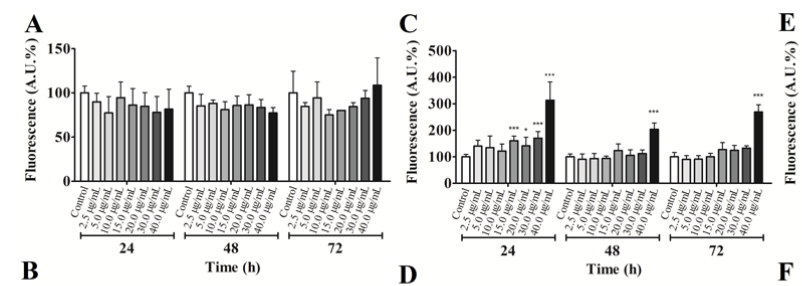

E
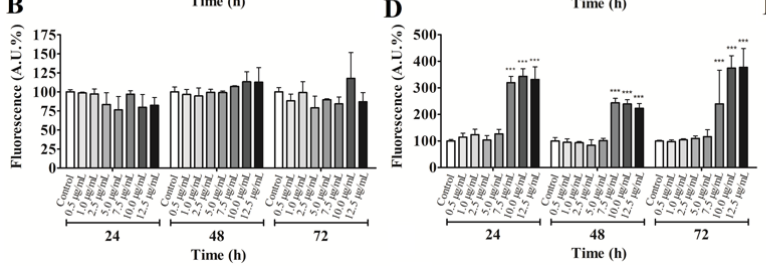

F
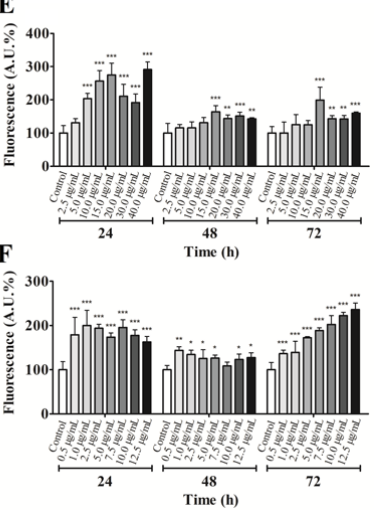